Journal of Research of the National Institute of Standards and Technology

[J. Res. Natl. Inst. Stand. Technol. 99, 201 (1994)]

Letter to the Editor

\title{
New Values for Silicon Reference Materials, Certified for Isotope Abundance Ratios
}

\section{P. De Bièvre and S. Valkiers}

Institute for Reference Materials and Measurements ${ }^{1}$, Commission of the European Communities, Joint Research Centre, B-2440, Geel, Belgium

and

\section{H. S. Peiser}

National Institute of Standards and Technology,

Gaithersburg, MD 20899-0001
New isotope abundance and relative atomic mass (atomic weight) values with low, hitherto unattained uncertainty - are reported for two previously described silicon reference materials using a well-known method with an improved isotope-ratio mass spectrometer. These ncw values are directly traceable to the SI, more specifically to the unit for amount of substance, the mole, and independent of the SI unit of mass and of the Avogadro constant. Besides the residual mass-spectrometric uncertainties, these new values depend in effect only on a recently published direct comparison of the cyclotron frequency in a Penning trap of ${ }^{28} \mathrm{Si}^{+}$with that of ${ }^{12} \mathrm{C}^{+}$.

Key words: absolute abundances; atomic weights; cyclotron frequencies; isotope abundances; isotope ratio mass spectrometry; isotope reference materials; Penning trap; relative atomic masses; reference material; silicon; silicon tetrafluoride.

Accepted: February 10, 1994
Two new silicon isotope reference materials (RMs) have previously been announced [1]: IRM$017^{2}$ in chips of a silicon crystal (distributed in samples of about $2 \mathrm{mmol}$ ) and IRM- $018^{2}$ in the chemical form of $\mathrm{SiO}_{2}$ (distributed in samples of about $0.1 \mathrm{~mol}$ ) [2]. An independent set of absolute measurements with an improved mass spectrometer [3] is now reported. Some further refinement of the gas mass-spectrometric measurement has been achieved. In that method $\mathrm{SiF}_{3}{ }^{+}$ions generated from a synthetic mixture of highly enriched specimens of $\mathrm{Si}$ isotopes are compared with these ions from the RMs of proven internal homogeneity [4]. Improved data analysis has in the meantime also been developed and adopted for all "standard atomic weight" evaluations by the Commission on Atomic Weights and Isotopic Abundances of the

${ }^{1}$ Formerly: Central Bureau for Nuclear Measurements.

${ }^{2}$ After the renaming of the Institute, these are now labelled IRMM-017 and IRMM-018.
International Union of Pure and Applied Chemistry [5].

The uncertainties of the measurements here described still depend mostly on the mass-spectrometrically derived isotope abundance ratios. However, these uncertainties now approach those of the best values of the relative atomic masses of the silicon isotopes. For these masses we have based our calculations on the recent direct comparison in a Penning trap of the cyclotron frequency of ${ }^{28} \mathrm{Si}^{+}$with that of ${ }^{12} \mathrm{C}^{+}[6]$. The derived ${ }^{28} \mathrm{Si}$ mass is uncertain by only $1 \times 10^{-8}$ and only $3 \times 10^{-9}$ higher than the value recently published by Audi and Wapstra [7] with a marginally lower estimated uncertainty by taking other measurements into consideration. Uncertainties in recognized values for the atomic masses of ${ }^{29} \mathrm{Si}$ and ${ }^{30} \mathrm{Si}$ are negligible because of their low abundances in terrestrial silicons.

Table 1 summarizes the new results. Their significance rests on: 
Table 1. Isotopic composition and $A_{\mathrm{r}}(\mathrm{Si})$ for both RMs. Expanded uncertainties, $U$, are indicated under the digits to which they relate and are computed on a two standard deviation basis.

\begin{tabular}{|c|c|c|c|c|}
\hline \multirow[b]{2}{*}{ Abundance ratio } & \multicolumn{2}{|c|}{ IRMM-017 } & \multicolumn{2}{|c|}{ IRMM-018 } \\
\hline & New values & $\begin{array}{l}\text { Previous } \\
\text { values [1] }\end{array}$ & New values & $\begin{array}{l}\text { Previous } \\
\text { values [1] }\end{array}$ \\
\hline $\begin{array}{l}n\left({ }^{29} \mathrm{Si}\right) / n\left({ }^{28} \mathrm{Si}\right) \\
n\left({ }^{30} \mathrm{Si}\right) / n\left({ }^{28} \mathrm{Si}\right)\end{array}$ & $\begin{array}{rl}0.050771 & 5 \\
6 & 6 \\
0.033488 & 9 \\
7 & 8\end{array}$ & $\begin{array}{r}0.05069 \\
12 \\
0.033 \quad 52 \\
10\end{array}$ & $\begin{array}{rrr}0.050844 & 2 \\
4 & 8 \\
0.033585 & 1 \\
6 & 6\end{array}$ & $\begin{array}{rr}0.050 & 83 \\
& 12 \\
0.03360 \\
10\end{array}$ \\
\hline $\begin{array}{l}\text { Amount (of } \\
\text { substance) } \\
\text { Fraction }\end{array}$ & & & & \\
\hline${ }^{28} \mathrm{Si}$ & 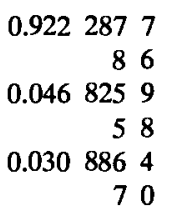 & $\begin{array}{r}0.922 \quad 33 \\
14 \\
0.04675 \\
71 \\
11 \\
0.030 \quad 92 \\
8\end{array}$ & $\begin{array}{rrr}0.922 & 144 & 0 \\
& 7 & 0 \\
0.046885 & 7 \\
4 & 2 \\
0.030970 & 3 \\
5 & 8\end{array}$ & $\begin{array}{rr}0.922 \quad 14 \\
& 14 \\
0.046 \quad 88 \\
& 11 \\
0.030 \quad 98 \\
8\end{array}$ \\
\hline $\begin{array}{l}\text { Relative mean } \\
\text { atomic mass } \\
\text { (atomic weight) } \\
A_{\mathrm{r}}(\mathrm{Si})\end{array}$ & $\begin{array}{r}28.085 \quad 408 \\
15\end{array}$ & $\begin{array}{r}28.08540 \\
19\end{array}$ & $\begin{array}{r}28.085 \quad 635 \\
12\end{array}$ & $\begin{array}{r}28.08565 \\
19\end{array}$ \\
\hline
\end{tabular}

1) the reduction of the uncertainties by one order of magnitude;

2) the direct traceability of these values to the mole, the SI unit for amount of substance, involving only relative mass measurements of the enriched samples, without any absolute mass measurement based on the kilogram;

3) the ability with these RMs to compare reliably silicon specimens at the $10^{-7}$ level of relative atomic mass (atomic weight) $A_{\mathrm{r}}(\mathrm{Si})$, a level at which many geological sources and processed materials can be differentiated;

4) the reliable intercomparisons of these isotopic RMs with Si SRM 990 of NIST [8] enable the reduced uncertainty to be transferred to the latter without much loss. A value of $A_{\mathrm{r}}(\mathrm{Si})=28.085$ $538 \pm 0.000018$ might be indicated compared with the NIST certified value from 1975 measurements of $A_{\mathrm{r}}(\mathrm{Si})=28.085526 \pm 0.000056$.

\section{References}

[1] S. Valkiers, P. De Bièvre, G. Lenaers, and H. S. Peiser, J. Res. Natl. Inst. Stand. Technol. 96, 617-619 (1991).

[2] S. Valkiers, G. Lenaers, and P. De Bièvre, Characterization of Two Silicon Isotope Reference Materials: IRMM Internal Report GE/R/MS/11/89.
[3] P. De Bièvre, S. Valkiers, H. S. Peiser, F. Schäfer, and P. Seyfried, P.T.B.-Mitteil. in press (1994).

[4] P. Seyfried, P. Becker, A. Kozdon, F. Lüdicke, F. Spieweck, J. Stümpel, H. Wagenbreth, D. Windisch, P. De Bièvre, H. H. Ku, G. Lenaers, T. J. Murphy, H. S. Peiser, and S. Valkiers, Z. Phys. B 87, 289-298 (1992).

[5] F. Schäfer, S. Valkiers, P. D. P. Taylor, P. De Bièvre, Int. J. Mass Spectrom. Ion Phys., in press (1994).

[6] R. Jertz, D. Beck, G. Bollen, J. Emmes, H.-J. Kluge, E. Schark, S. Schwarz, Schweighard, and P. Sonne, Physica Scripta 48, 399-404 (1993).

[7] G. Audi and A. H. Wapstra, Nucl. Phys. A565, 1-65 (1993).

[8] I. L. Barnes, L. J. Moore, L. A. Machlan, T. J. Murphy, and W. R. Shields, J. Res. Natl. Bur. Stand. (U.S.) 79A, 727-735 (1976).

About the authors: P. De Bièvre is a PhD from Gent University and also Professor in Isotope Mass Spectrometry at Antwerpen University in addition to his position at IRMM. S. Valkiers received a degree in chemical engineering in 1976 from HIK College of Technology, Geel, Belgium. H. S. Peiser, now retired, was at one time Chief of the Crystal Chemistry Section at the National Bureau of Standards (now the National Institute of Standards and Technology). The National Institute of Standards and Technology is an agency of the Technology Administration, U.S. Department of Commerce. 